\title{
Geomorphic hazards and intense rainfall: the case study of the Recco Stream catchment (Eastern Liguria, Italy)
}

\author{
F. Faccini ${ }^{1}$, A. Robbiano ${ }^{2}$, and A. Sacchini ${ }^{1}$ \\ ${ }^{1}$ University of Genoa, Corso Europa 26, Genoa 16132, Italy \\ ${ }^{2}$ via Capolungo 46, Genoa 16167, Italy \\ Correspondence to: F. Faccini (faccini@unige.it)
}

Received: 8 August 2011 - Accepted: 21 February 2012 - Published: 11 April 2012

\begin{abstract}
A critical pluviometric event occurred in the central-eastern Ligurian Riviera, $15 \mathrm{~km}$ from Genoa, on 1 June 2007. This event caused landslides and hydraulic problems between Sori and Camogli and in the inland area of the Recco Valley.

An analysis of the heavy rainfall was conducted.
\end{abstract} Hourly precipitation data revealed a critical event between 04:00 a.m. and 07:00 a.m. local time, with more than $220 \mathrm{~mm}$ of precipitation over three hours.

Slope movements were mainly debris flows that detached from the lateral valleys of the Recco Stream catchment and from well-maintained, wooded slopes that were also characterised by cultivated terraces.

Numerous slide planes corresponded to the interface between the surface cover and the underlying bedrock, which presents an unfavourable geologic structure in terms of stability assessment.

In most cases, the displaced material had a limited thickness. Debris cover was rapidly channelled along small valleys, which controlled the critical hydraulic conditions in the secondary drainage network.

Man-made drainage systems were partially or totally blocked in a very short time and, like the natural watercourses, accumulated thick and extensive alluvial fans.

Most of the instability phenomena occurred in areas that had been designated medium or low-risk areas during land planning, and in sectors that were defined as stable, because they lacked geomorphic indicators connected to landslide risks.

The above considerations highlight some gaps of the Recco Stream Master Plan. Therefore, to update this land planning tool, it is necessary to extensively investigate local geomorphological characteristics and to adopt a different method for assigning weights to the geohazard maps.

\section{Introduction}

It is widely acknowledged that current climate changes have rainfall tropicalisation effects at temperate latitudes (IPCC, 2007). Sudden, heavy precipitation events frequently interrupt long dry periods; extreme events, which can deliver more than $100 \mathrm{~mm} \mathrm{~h}^{-1}$ in Liguria, cause geomorphological hazards, both on slopes and within the hydrographic network (Crosta and Frattini, 2000; Luino, 2005; Jakob and Lambert, 2009).

The present paper investigates a rainfall event that occurred on 1 June 2007 in the eastern sector of the Paradiso Gulf, central-eastern Ligurian Riviera (Fig. 1). In this area, which is typical of the Mediterranean coast, a heavy and short rainfall event triggered a number of shallow landslides and several hydrographic network instabilities. Public infrastructure damage was estimated to be more than 1.5 million euros. Damage affected communication routes for both pedestrians and vehicles, buildings and the terraced slope tracts used for farming. A number of similar events occurred at this location over the last several decades (Faccini et al., 2005, 2009) and the well-known flash floods of 2010 and 2011 events in the Genoa municipality and surrounding areas caused human losses (Sacchini et al., 2011; Faccini et al., 2012).

The current Basin Master Plan (Provincia di Genova, 2002) identifies the geomorphological hazards in the study area as medium to high; only some slope sectors are classified as low hazard. The hazard level is never considered very high in the absence of active or dormant landslides.

An analysis of the instability features that were triggered on 1 June 2007 facilitated the identification of several geological factors that can represent potential geomorphological hazard phenomena along slopes with apparently stable conditions or without active processes. Furthermore, an infiltration model was applied for probabilistic stability analysis and 


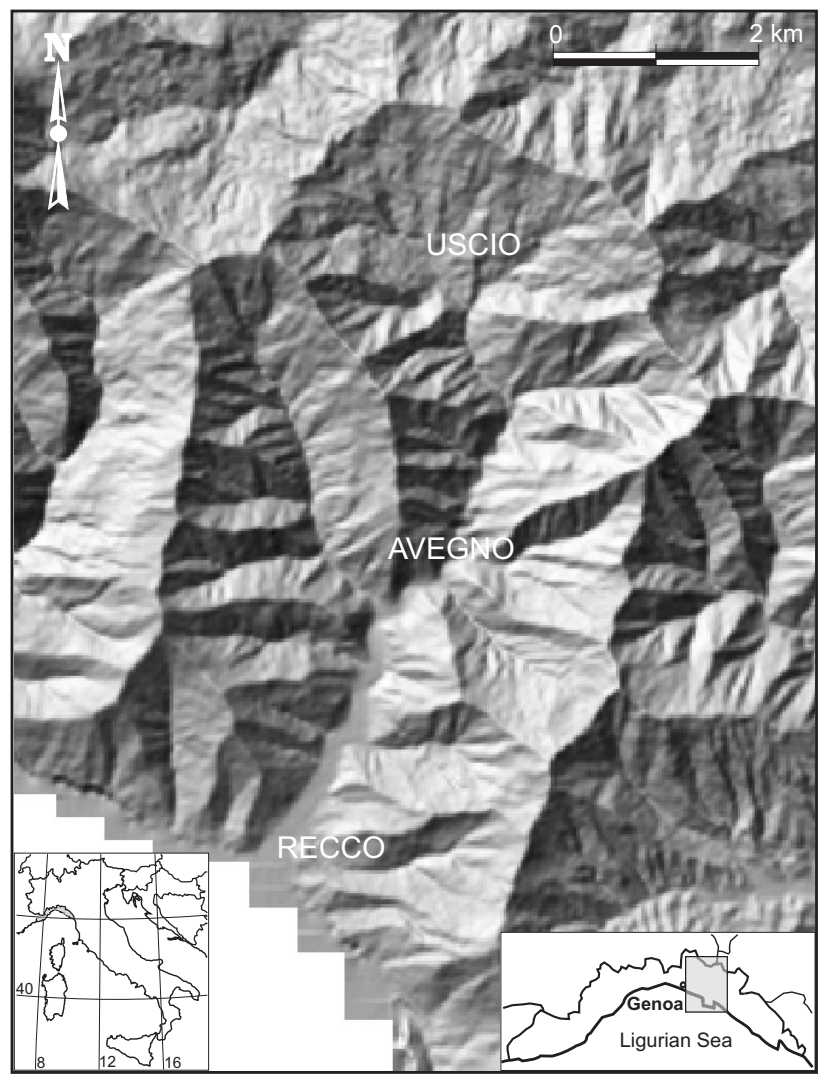

Fig. 1. Geographic sketch map of Recco Stream catchment (DTM model).

a GIS map was introduced as a tool for defining zones with different geohazards.

It is important that valuable lessons are learnt from extensive discussions on each disaster event.

The final aim of this study is to discuss the case study of the Recco Stream catchment, representing situations that are increasingly recurrent in Liguria, which witnesses, on one hand, the effects of the current climate change, on the other hand, the need to improve land planning tools.

\section{Research method}

A pluviometric analysis of the event was conducted based on data collected at both the stations in the Recco Stream catchment (Colonia Arnaldi and Polanesi) and at suitable adjacent stations (Genoa, Bargagli, Bavari and Chiavari). Hourly rainfall data were analysed along with event data and these were compared to climatic averages; then the meteorological conditions that triggered rainfall were analysed. Weather radar data have been used as a tool for providing a highly valuable contribution to the analysis of rainfall, especially for high intensity, spatially limited storms, which are often affected by strong spatial gradients.
Although no discharge measurement stations are installed in the Recco Stream, peak discharge has been assessed by means of post-flood observations (survey of cross-sections and high water marks, application of hydraulic equations) to evaluate geomorphic effects of this flash flood in comparison with previous floods.

To provide risk assessment and action priorities, the hydrogeological instabilities and criticalities that occurred along the hydrographic network were inventoried by drawing appropriate survey data forms. For each of the slope instabilities, location, slope exposure, altitude, geometry, movement classification, and triggering mechanisms were described. Location, bed orientation and condition, altitude, and geometry were recorded for instability phenomena in the hydrographic network (Table 1).

These phenomena were inventoried and georeferenced so as to compare them with the current land planning.

During the on-site survey, about twenty samples of soil were taken for laboratory testing to develop an infiltration model. Based on the well-known Green and Ampt method (1911) - which has been recently applied by Muntohar and Jiun Liao (2010) - the Pradel-Raad method (1993) was followed: it has already been applied in Liguria and in Italy (Crosta, 1994, 1998).

A set of historical maps of the Recco Stream floodplain dating from 18th century was collected for a comparative analysis; in particular, maps dated 1815-1823 ("Carta degli Stati Sardi di Terraferma”, Map of the Mainland Sardinian States), 1878, 1936 (“Tavolette serie 25v dell'Istituto Geografico Militare Italiano, Topographic maps produced by Italian Military Geographic Institute) and 1996 (Carta Tecnica Regionale, Technical Map of the Ligurian Region) were utilized.

As current land planning tools are relatively inadequate to describe risk conditions, a GIS-based model was developed to achieve characterisation of slope susceptibility to rainfalltriggered instabilities. Different weights assigned to geological and geomorphological parameters led to a draft of a new geohazard map.

The morphological characteristics of the valley and current climatic trends caused the statistical approach to deviate significantly from reality.

The research method that has been followed here allows to evaluate in an integrated manner all aspects associated with a disaster event such as this and does not limit the approach to the hydrological and statistical point of view (Giannecchini, 2006; Guzzetti et al., 2008; Cevasco et al., 2010).

\section{Information about the study area}

\subsection{Geographical outlines}

The Recco Stream catchment lies on the Tyrrhenian slope of the Ligurian Apennines, at the western base of the Portofino 
Table 1. Examples of survey data form for: (a) slope instabilities, (b) instability phenomena in the hydrographic network.

\begin{tabular}{l|l|}
\hline \hline A & HYDROGEOLOGICAL CRITICITIES DATA FORM \\
JUNE,1, 2007 EVENT, RECCO MUNICIPALTY
\end{tabular}

Promontory, approximately $15 \mathrm{~km}$ east of Genoa (Fig. 1). It is a generally rural area, except for Recco and a few other towns and it is characterized by wooded slopes, especially on the higher sectors, and terraced slopes for extensive farming.

This catchment has an average altitude of $293 \mathrm{~m}$ a.s.l. and a surface area of $22.4 \mathrm{~km}^{2}$. It includes the municipalities of Avegno, Uscio and Recco, which have a total population of approximately 15000 . The catchment is oriented in a NNESSW direction, its maximum altitude $729 \mathrm{~m}$ (Mt. Borgo), and its average slope steepness is nearly $60 \%$. The stream flows into the well-known Recco Bay and has two relevant tributaries on its hydrographic right: the Terrile Stream at high altitude and the Arbora Stream at moderate altitude.

The pluviometric characteristics of the area are based on data collected over several decades from the Polanesi and Colonia Arnaldi stations, which are located on the orographic right of the Recco catchment at altitudes of approximately $50 \mathrm{~m}$ and $600 \mathrm{~m}$, respectively. Kriging interpolation data collected at a few adjacent stations show that the mean annual precipitation varies between 1300 and $1400 \mathrm{~mm}$ along the coast, and increases to $1700-1800 \mathrm{~mm}$ between 500 and $700 \mathrm{~m}$.

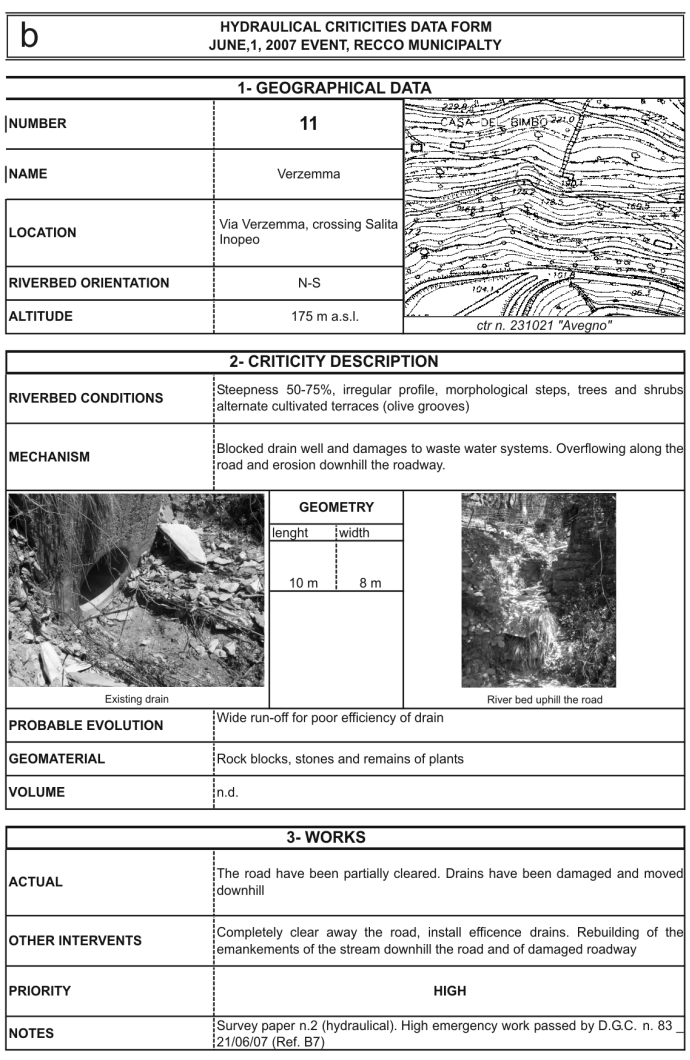

Rainfall is distributed throughout the year; maximum values in October and November are $220-240 \mathrm{~mm}$ at Colonia Arnaldi and $165-170 \mathrm{~mm}$ at Polanesi. The monthly minimum values are recorded in June and July: $60-90 \mathrm{~mm}$ at Colonia Arnaldi and 35-60 mm at Polanesi. The pluviometric regime is Mediterranean, but is transitional to the continental regime.

Seasonal differences between spring, autumn and winter are hardly relevant, and summer does not exhibit dramatically lower rainfall. At Polanesi, the mean rainfall observed for a three-month period is $385 \mathrm{~mm}$ in winter, $444 \mathrm{~mm}$ in autumn and $300 \mathrm{~mm}$ in spring; in the three-month summer period, the mean rainfall still exceeds $150 \mathrm{~mm}$. In the upperbasin portions (Colonia Arnaldi weather station), these mean values are approximately $555 \mathrm{~mm}$ (winter), $596 \mathrm{~mm}$ (autumn), $489 \mathrm{~mm}$ (spring) and $247 \mathrm{~mm}$ (summer).

Mean temperatures vary between $15.8^{\circ} \mathrm{C}$ at Polanesi and $12.6^{\circ} \mathrm{C}$ at Colonia Arnaldi. July is the hottest month, with temperatures of $24^{\circ} \mathrm{C}$ along the coast and nearly $21^{\circ} \mathrm{C}$ at $600 \mathrm{~m}$ a.s.l. January is the coldest month, with mean temperatures between $8.6^{\circ} \mathrm{C}$ at Polanesi and $5.4^{\circ} \mathrm{C}$ at Colonia Arnaldi. Based on the ombrothermic index (Gaussen, 1956), there are no dry periods in the upper-basin portions, and only July is dry along the coast. 


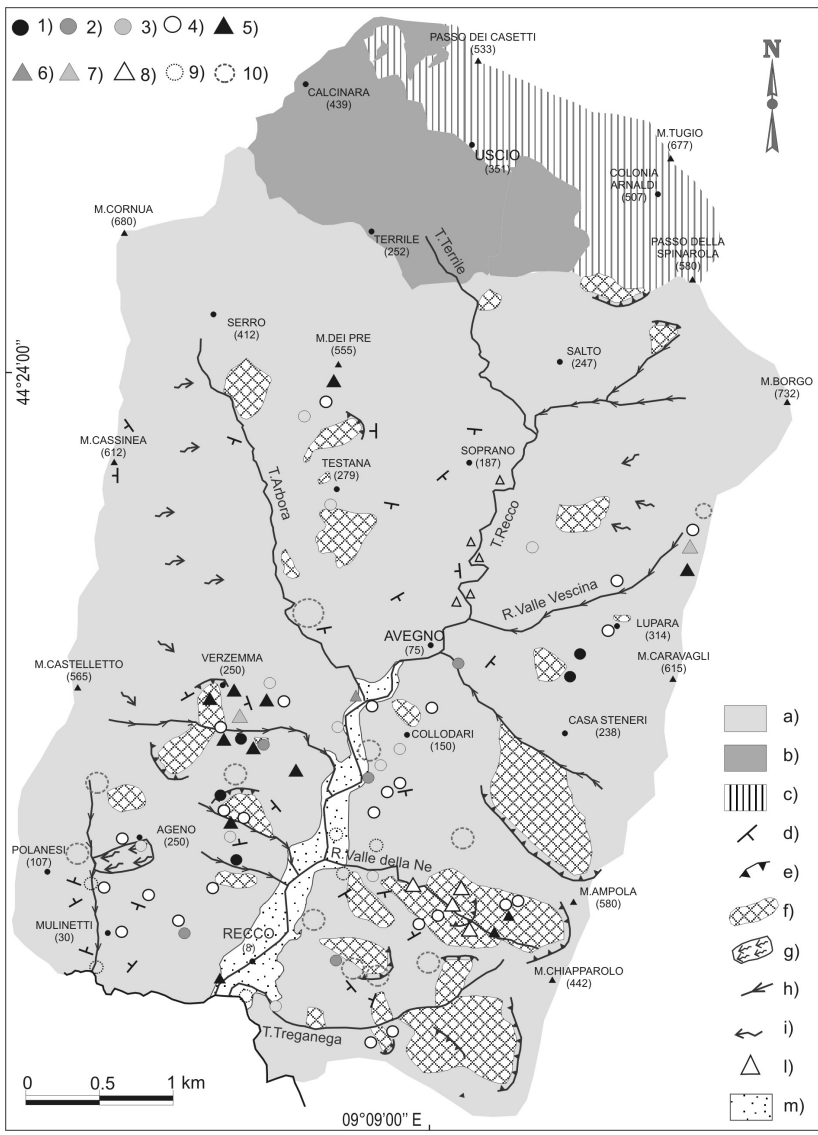

Fig. 2. Geomorphological sketch map of Recco Stream catchment. Geological Data: (a) Mt. Antola limestone; (b) Mt. Verzi slates; (c) Manganesiferous shales; (d) Bedding attitude. GEOMORPHoLOGICAL DATA: (e) Inactive landslide scarp; (f) Relict or inactive complex landslides, palaeolandslides; (g) Solifluction; (h) Thalweg erosion; (i) Surface run off areas; (l) Alluvial or mixed fan; (m) Recent or actual alluvial deposit. Landslides reported after 1 June 2007 event: (1) hydrogeological instabilities at very high risk; (2) high risk; (3) medium risk; (4) low risk; (5) hydraulic criticities at very high risk; (6) high risk; (7) medium risk; (8) low risk; (9) other criticities; (10) other areas characterized by landslides or hydraulic criticities as reported by citizens.

\subsection{Geological and geomorphological setting}

The geological setting of central-eastern Liguria is characterised by the Mt. Antola unit, which overlies the Mt. Gottero unit.

The Mt. Antola unit, which almost entirely comprises the basin of the Recco Stream (Fig. 2), is represented by the limestone formation of Mt. Antola. In the study area, the Gottero unit is composed of the slates formation of Mt. Verzi and the manganesiferous shales (Italian Geological Survey, Servizio Geologico d'Italia, 1968).

The Mt. Antola Formation is a flysch sequence of limestone-marly turbidites, including thick layers of cal- carenites that have a predominant silicoclastic component, marls, limestone marls and marly argillites that are intercalated with thin layers of hemipelagic argillites. Regional structural analyses identified at least four deformation stages that are characterised by both ductile and fragile events (Corsi et al., 2001); bed attitude can vary and shows frequent series inversion.

The Mt. Gottero unit can be observed in the upper-basin portion. The slates formation of Mt. Verzi outcrops between Uscio and Calcinara in the Terrile Stream basin and is composed of marls, limestone marls and marly limestones in graded layers, from medium to thick, with very thin interlayers of carbonate-free pelites. In this regard it is noted that the Ligurian slate manufacturing still remains an important feature of the local economy: extremely sought-after for the realisation of billiard tables, it is also used for roof coverings and as a building material. Slate is also employed to make objects and artworks nowadays as it was in the past.

The manganesiferous shales extend over the top sector of the basin between Mt. Rosso and Mt. Borgo and are composed of dark, manganesiferous argillites, siltstones and fine arenites in graded layers. The bed attitude often varies in relation to the deformational history (Van Zutphen et al., 1985).

The geomorphological dynamics of the Recco Stream basin describe processes related to tectonic action, gravity, running water and anthropogenic activity.

Due to the effects of high relief energy and tectonics on hydrography, the water courses exhibit an angular network and feature a maximum hierarchical order of five. The final section of the Recco Stream is perpendicular to the coastline and varies between braided and meandering, indicating its limited maturity. The water stream is thus at an erosive stage, and solid transport is high, especially during exceptional floods; a flow of $350-400 \mathrm{~m}^{3} \mathrm{~s}^{-1}$ has occurred once in a 200-yr period (data from the Basin Master Plan, Provincia di Genova, 2002). Historic analysis identified at least four major floods linked to strong meteorological events in 1911, 1961, 1964 and 1993.

The valley floor has been covered by urban development and Recco town extends for one kilometre before the stream flows into the sea.

Both slope steepness and the pluviometric regime have encouraged erosive action by channelled and running waters that generate incised stream valleys and erosive-stage banks. Slopes are widely characterized by generally thin covers, which were terraced by man for farming.

Gravity landforms are represented by several landslides, which have probably been triggered under various climatic conditions. About twenty ancient landslide bodies have been inventoried in the study area and are classified as inactive to relict. These bodies are preferential sites for hamlets. The controlling geological factor is the lithological heterogeneity of the Flysch, which features intercalated hard and weak rock lithologies. 


\section{Information about the target event rainfall}

From a meteorological point of view, the 1 June 2007 event can be described as a depression associated with a normal width through coming in the Mediterranean at about 12:00 a.m. The Ligurian Sea was relatively warm as a result of the hot, dry spring. Cold, wet south-western winds converged over the sea at medium-low atmospheric levels near the Portofino Promontory. The orographic effect of this convergence caused stormy pre-frontal activity, and generated a stationary supercell system that subsequently produced heavy rainfall. Rainfall accumulation, intensity and duration recorded at Polanesi station were analysed. The analysed flood was associated with intense rainfall that exceeded $240 \mathrm{~mm}$ over three hours, three times the average precipitation value for June (Fig. 3a). The most intense rainfall was experienced in the lower sector of the Recco Stream valley (Fig. 3b), although the flood affected the entire catchment with different levels of intensity.

The 1 June 2007 event was characterised by a main precipitation period with an intensity of $146 \mathrm{~mm} \mathrm{~h}^{-1}$, which started at 05:00 a.m. and continued for about one hour. Earlier and later secondary downpours had intensities between 35 and $40 \mathrm{~mm} \mathrm{~h}^{-1}$ and similar durations (Fig. 3c). The most intensive downpours struck western Portofino Promontory coastline with a quasi-stationary supercell while the thunderstorm extended its influence over Northern Italy, but less intensively. Later, the pluviometric peak thunderstorm moved eastward losing intensity and rainfall stopped (Fig. 3d).

These data for one, two, and three-hour periods are highly notable for Eastern Liguria. The exponential relationships between these data and the pluviometrical threshold exceed typical values (Fig. 4) at local, regional and global levels (Caine, 1980; Cancelli and Nova, 1985; Giannecchini, 2006; Faccini et al., 2005, 2009).

This event affected the Recco Stream by causing a sudden flood with major solid transport and erosion along the scarps and unprotected embankments. In a run-off time of about one hour and a maximum hourly precipitation, averaged in the catchment, of over $80 \mathrm{~mm}$ are considered, a flow of more than $450 \mathrm{~m}^{3} \mathrm{~s}^{1}$ occurred. According to the Master Plan this discharge exceeded a return period of $500 \mathrm{yr}$. This value can also be compared to soil effects in Recco town.

In the Recco town centre, roads were flooded, the hamlets on the adjacent hills were isolated, the basement of the hospital was flooded, schools were closed, and the right stream embankment collapsed at the stream mouth.

The Recco Stream overflowed where it is crossed by the motorway bridge. On the motorway viaduct, the water was one metre high, and the railway line had to be closed for several hours.

At Avegno, the stream overflowed the embankments at the Vexina bridge and several houses and shops were flooded. The Testana hamlet was isolated by a landslide and landslides also occurred on the municipality routes in Uscio.
The mobilised debris flows rapidly channelled along watersheds and depressions, causing critical hydraulic conditions in the secondary hydrographic network and reduced outflow. Culverts under roads were insufficiently dimensioned.

Artificial canals at the road intersections were rapidly obstructed, forming huge deposits.

These features were evident throughout the middle course of the Recco Stream, between Avegno and Recco near the Verzemma Stream and the Ne Valley, where the lack of a downstream drainage canal precluded appropriate flood outflow. They also caused the formation of alluvial fans on the valley floor.

\section{Results}

Approximately fifty critical situations were reported in the whole catchment. Most were concentrated in the middle and lower basin sectors. Two-thirds of the cases were slope geomorphological instabilities, such as rock falls, slides, debris flows and mixed processes (slide-debris flow and falldebris flow), having a median thickness of less than two metres. In approximately three-quarters of the observed cases, the gravitational phenomena that occurred following the 1 June 2007 event can be defined as debris flows and debris slides (Varnes, 1978, 1984; Crozier, 1986; Cruden and Varnes, 1996) and were triggered along the side valleys of the Recco Stream.

Slope movements occurred exclusively on outcrops of the limestone formation of Mt. Antola. In-situ observations highlighted the fact that a number of sliding planes associated with landslide phenomena corresponded to the interface between the debris cover and the bedrock. Because they dipped towards the thalweg, they had the same position as the slope planes.

The triggering mechanisms were caused by maximum shear stress under peak conditions (Sassa, 1985).

The estimated risk was typically very high for the hydraulic criticalities and high or very high for about one-third of the slope instabilities listed in the inventory.

Distribution of grain size showed well-graded soils containing significant gravel $(1 \%-45 \%)$, sand $(3 \%-41 \%)$ and clay + silt $(29 \%-92 \%)$. The liquid limit varied between 24 and 49 and the plasticity index ranged between 10 and 23. Soils were mainly classified as CL under the Unified Soil Classification System, and fewer SC, GC and ML classes were also observed.

A literature review was conducted to compare the 1 June 2007 event that occurred in the Recco catchment with other events that were observed in the Mediterranean region. Figure 4a shows landslide-triggering thresholds in a rainfall intensity vs duration diagram, according to Caine (1980) and Cancelli and Nova (1985), with curves computed for worldwide and Italian landslides respectively. 

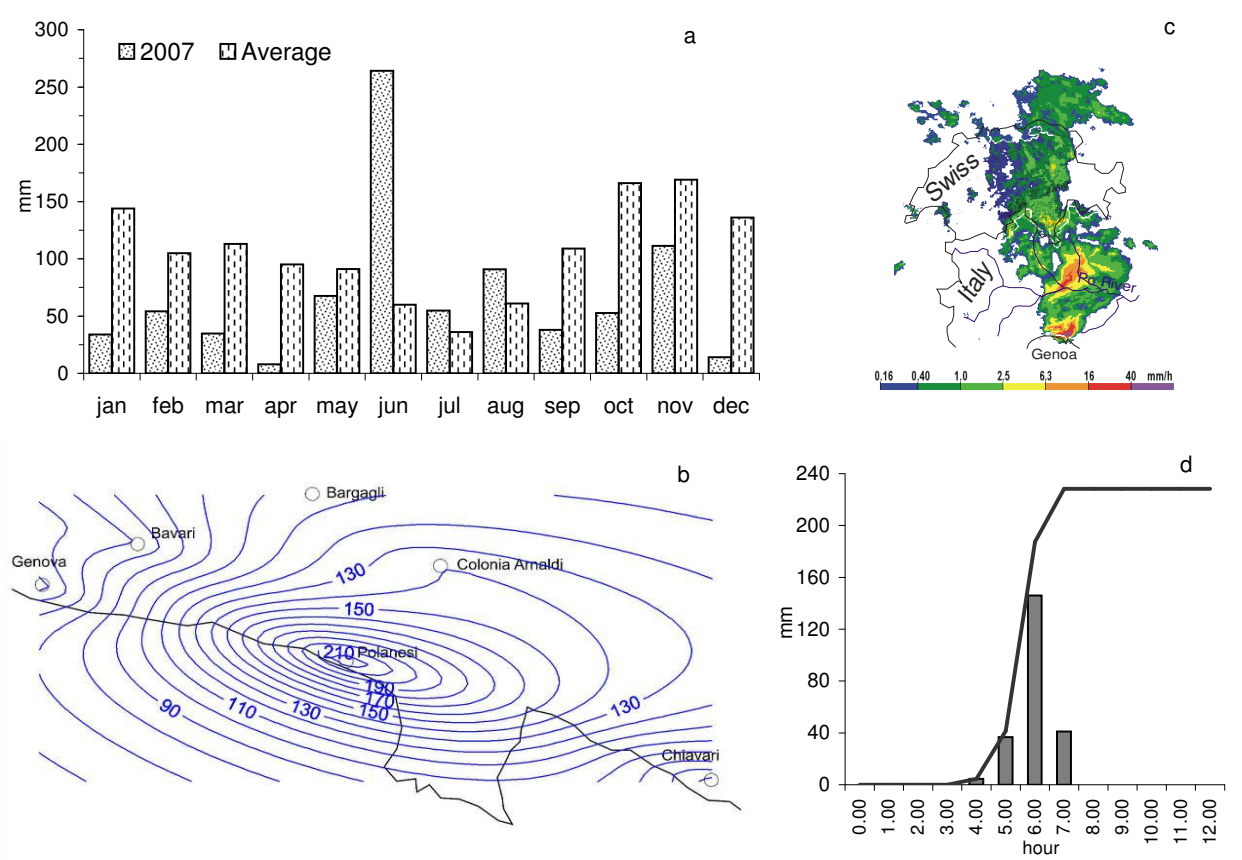

Fig. 3. Meteorological and climatic sketch: monthly rainfall distribution at Polanesi station (a); isohyeth map (mm) of $1 \mathrm{June} 2007$ event (b); Swiss radar image of pluviometric event (www.landi.ch/niederschlagsradar). (c); event hyetogram recorded at Polanesi station (d).

Data that were collected from events that occurred in Liguria (Genoa, Camogli, Sturla Valley, Lavagna Valley, Tigullio Gulf and Recco) show a good fit to these curves, while that 1 June 2007 event for one, two and three-hour periods generally exceeds previous ones.

Based on data collected at the stations in the Recco Stream catchment, pluviometric analysis of the generalized extreme values distribution was drawn following the Gumbel method (1941, 1958). The parameters a and n, referring to the relation $\mathrm{h}=\mathrm{a} \mathrm{t}^{n}$, which links rainstorm duration $\mathrm{t}$ to rainfall depth $\mathrm{h}$, indicated in the Basin Master Plan for return periods of 10, 50, 100, 200 and 500 years, were identified. According to the processed data, the return period of more than 500 years is valid not only for the whole event, but also for shorter durations (e.g. 1 and 2 h, Fig. 4b).

Precipitation data recorded at the Chiavari and Genoa stations, which are over $100 \mathrm{yr}$ old, show that about one-third of annual precipitation occurs in autumn and that there is an average of 84 rainy days per year. However, $70 \%-75 \%$ of these days experience precipitation of less than $1 \mathrm{~mm} \mathrm{~d}^{1}$; $10 \%$ of rainy days receive between 10 and $100 \mathrm{~mm} / \mathrm{d}$, and less than one day per year experiences a critical event like the analysed flood on average (Fig. 5).

The Pradel and Raad (1993) infiltration model was applied to assess the permeability threshold in relation to possible triggers for shallow landslides on homogeneous soils (Fig. 4b). The time required to saturate a certain soil thickness depends on the permeability coefficient, porosity and capillarity, approximately $10^{-5} \mathrm{~m} \mathrm{~s}^{1}, 20 \%-30 \%$ and $0.3-$
$0.4 \mathrm{~m}$, respectively. In this case, for a cover soil with median thickness of one metre, a precipitation event with a return period between 50 and 100 years requires between two and three hours to saturate the soil. Consequently, a precipitation intensity of $50-60 \mathrm{~mm} \mathrm{~h}^{-1}$ over this duration yields a permeability threshold of $10^{-5} \mathrm{~m} \mathrm{~s}^{-1}$. This rate can be compared to typical values for the determined granulometric spindle, so that geohazard of thin covers is higher than that recorded in the Master Plan.

More than $70 \%$ of the listed cases occurred on moderately steep slopes with gradients between $20 \%$ and $35 \%$; almost $15 \%$ of the cases occurred on slopes with a steepness of less than $20 \%$ and no cases occurred on very steep slopes of more than $75 \%$ (Fig. 6a).

More than half of the instabilities occurred on wooded slopes with a mixed coppice and the remaining instabilities occurred on farmed or abandoned terraced slopes (Fig. 6b). With respect to geomorphic conditions, $40 \%$ of the listed cases represented colluvial deposits of limited thickness, $25 \%$ of the cases represented eluvial deposits, and about $12 \%$ represented bedrocks with unfavourable structural conditions. Less than $25 \%$ of the surveyed cases occurred within huge, ancient landslide bodies (Fig. 6c).

Notably, no criticality was observed in sectors with a very high geomorphic hazard potential. Less than $50 \%$ of the instabilities occurred on slopes that were classified as highly hazardous, more than $40 \%$ on slopes that were classified as moderately hazardous, and slightly more than $10 \%$ on slopes classified as lowly hazardous (Fig. 6d). 

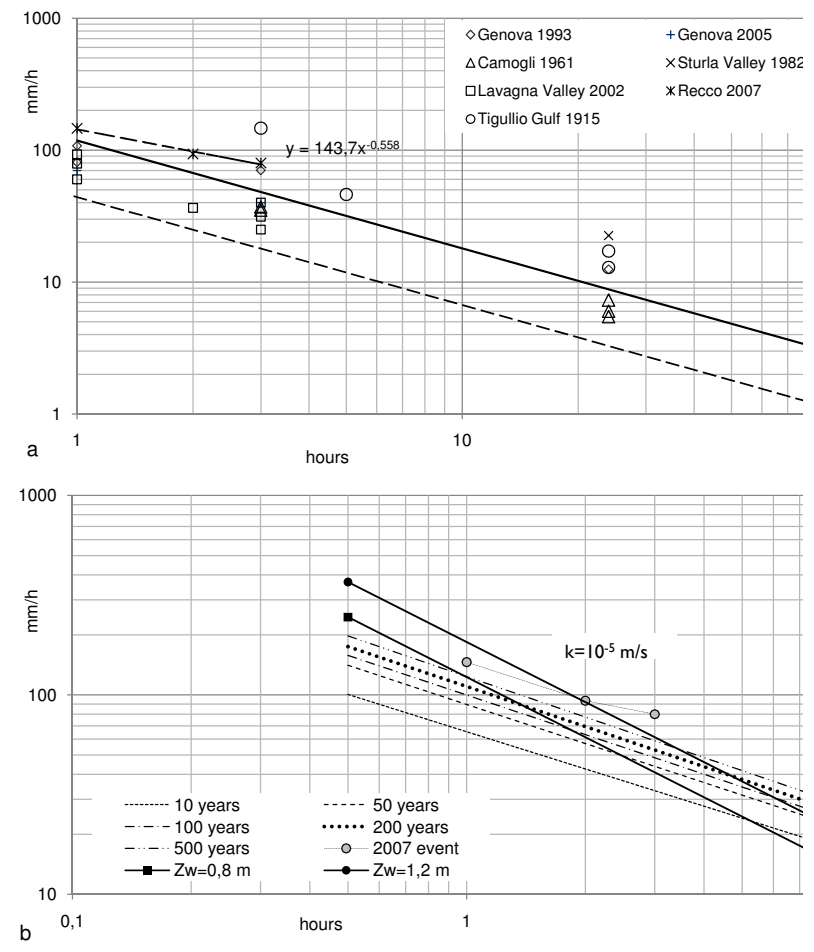

Fig. 4. Rainfall intensity vs duration curves: landslides triggering thresholds according to Cancelli and Nova (1985, dashed lines) and Caine (1980, bold lines) compared to events recorded in Liguria (a); critical saturation thickness $\left(Z_{\mathrm{W}}\right)$ for different return periods and permeability threshold - k compared to the 2007 event (b; Pradel and Raad, 1993).

\section{Discussion}

By comparing the surveyed hydrogeological instabilities with the base cartography derived from the Basin Master Plan, several evaluations can be drawn (Fig. 7a).

The Basin Master Plan classified areas with different hazard degrees (low, medium, high and very high). Most of the instability phenomena occurred in areas that had been designated medium or low-risk areas during land planning, and in sectors that were defined as stable, because they lacked geomorphic indicators of potential landslide risks.

Less than one-fourth of the studied instability processes occurred in areas featuring inactive or relict mass movements, and instabilities were not recorded in areas that were listed as active or dormant landslides.

Consistent with the cover thickness of slopes in the Master Plan geomorphological map, all of the covers mobilised by the pluviometric event had a thickness of less than two metres.

Based on these considerations, the Basin Master Plan must be updated by completing an in-depth study of geomorpho- a

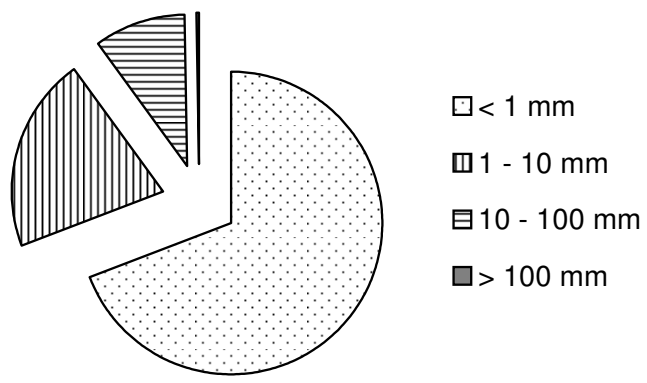

$\mathrm{b}$

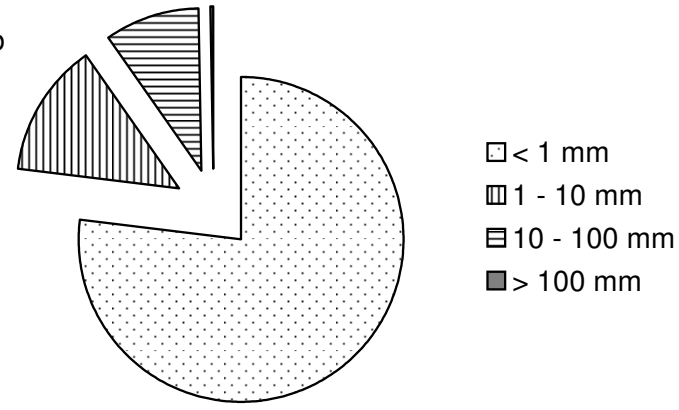

Fig. 5. Percent frequency of daily rainfall in Genoa (a) and Chiavari (b).
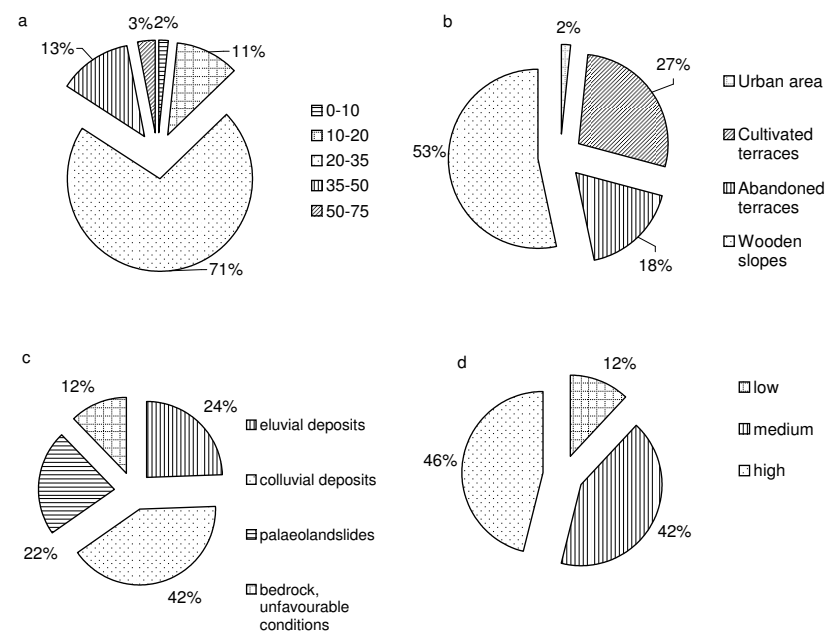

『low

四medium

$\square$ high

Fig. 6. Analysis of reported critical situations vs. acclivity (a), land use (b), geomorphological asset (c) and vulnerability (d).

logical landforms and processes. Specifically, a new method is required for calibrating the weights on the synthesis map and the geomorphological hazards map.

The bedrock attitude was considered irrelevant in the hazards map, but it must be considered along with coverage thickness. The studied event demonstrated that thin, loose covers, even in terraces, may become unstable if hydrological maximums occur, particularly if they are associated with heterogeneous rock masses and unfavourable dips. These 

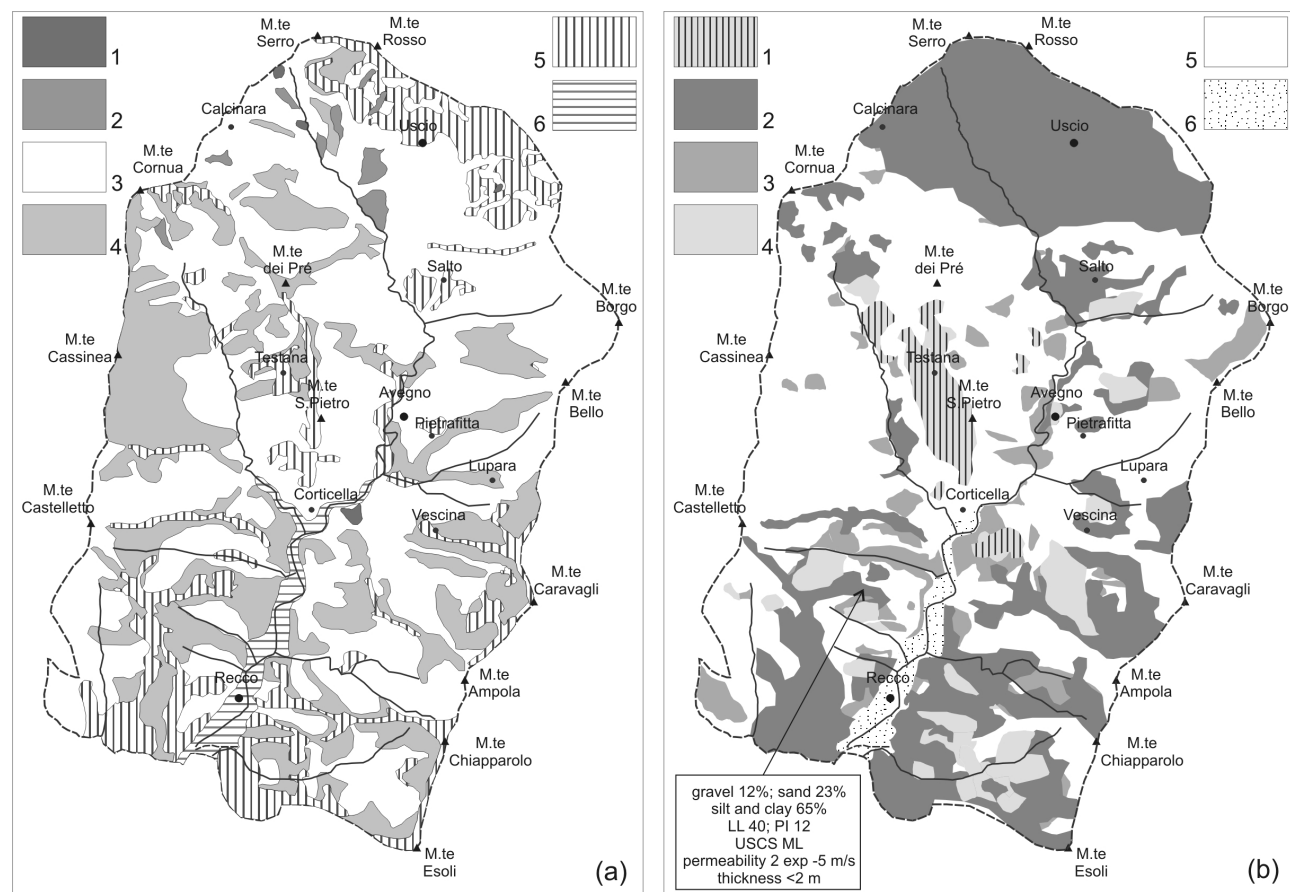

Fig. 7. (a) Geohazard map (modified from Recco Stream catchment Master Plan): 1. very high, 2. high (only dormant landslides), 3. high, 4. medium, 5. low, 6. very low. (b) Example of GIS-based model map for susceptibility of slopes to rainfall-triggered instability: 1. thin debris cover on unfavourable bed attitude, 2. thin debris covers, 3. thick debris covers, 4. palaeolandslides, 5. outcropping bedrock, 6. alluvial deposits.
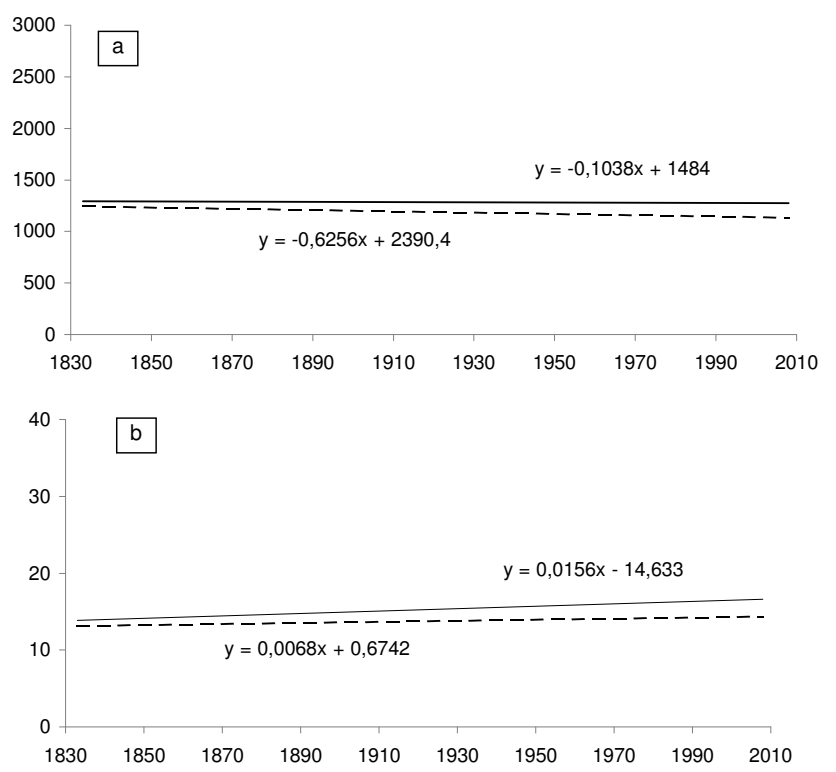

Fig. 8. Annual rainfall trend at Genoa (bold lines) and Chiavari (dashed lines): (a) height ( $\mathrm{mm})$, (b) precipitation rate $\left(\mathrm{mm}_{\text {days }}{ }^{-1}\right)$. considerations could also be applied to other Ligurian basins that exhibit the same conditions.

Figure 7b shows a few layers: steepness, bed attitude and cover thickness highlight a good agreement with shallow landslides that were triggered during the event. An adequate use of weights, together with characteristics of debris covers (grain size and permeability), helps to define susceptibility of slopes to rainfall-triggered instability.

On the other hand, according to the rainfall frequencies recorded over more than $100 \mathrm{yr}$ at the stations near the study area, a critical event should have a return period of more than $500 \mathrm{yr}$, consistent with the result provided by the hydrogeological probabilistic approach: according to it the recorded precipitation intensity is more than $140 \mathrm{~mm} \mathrm{~h}^{-1}$ (Fig. 4b).

The time series of annual rainfall, which describes average rainfalls between 1200 and $1300 \mathrm{~mm}$, does not highlight major changes (Fig. 8a). Although there are an average of 280 dry days annually, a positive correlation over time shows an increase in daily precipitation rate (Fig. 8b), already described by Pasquale et al. (1994) and Russo et al. (2000). This trend increases the possibility of experiencing intense precipitation events, and of exceeding the trigger thresholds for hydrogeological instabilities.

It is important to highlight that at least four major floods occurred during the 20th century in the Recco Stream catchment, and that events like the one studied occurred in 

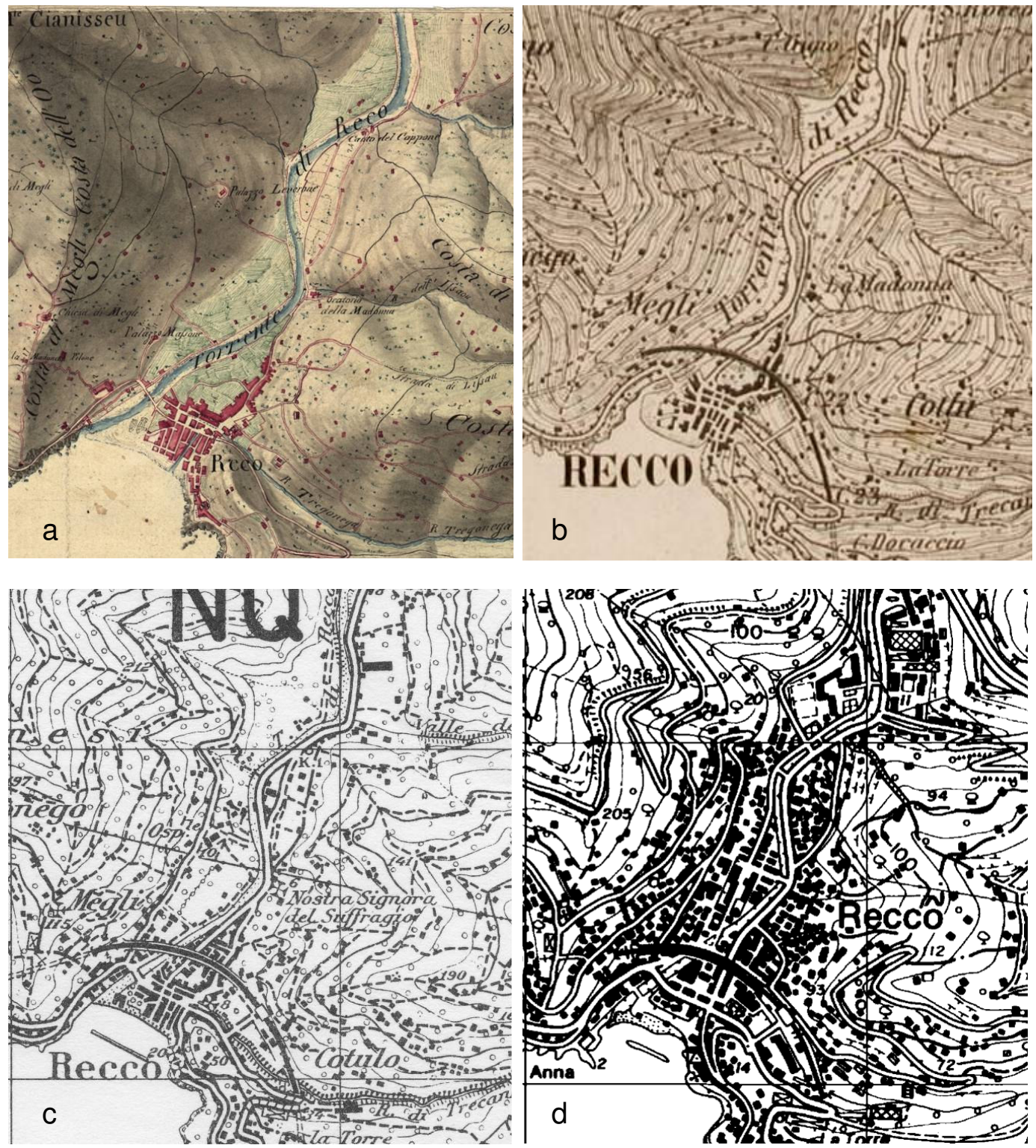

Fig. 9. Topographic map of Recco Stream floodplain: (a) 1815-1823 (“Carta degli Stati Sardi di Terraferma”), (b) 1878 and (c) 1936 ("Tavolette serie 25v dell'Istituto Geografico Militare Italiano), (d) 1996 (Carta Tecnica Regionale).

the autumn of the same year and in 2009. In the 2009 event, precipitation exceeded $250 \mathrm{~mm}$ in $24 \mathrm{~h}$, and maximum values of more than $50 \mathrm{~mm} \mathrm{~h}^{-1}$ were recorded. This event caused flooding throughout the hydrographic network, major solid transportation and riverbed erosion. Similar events took place over the last decade in Liguria (Faccini et al., 2005, 2009).

Anthropogenic changes in land use significantly influence hazard concerns and slope dynamics. Between the Middle Ages and the Industrial Age, slope farming settlements gradually increased, causing major changes in land use. Farm terraces were constructed and the inhabitants of the slope hamlets altered the geomorphological arrangement and the hydrogeological balances of the area.

In the first decades of XIX century, the Recco Stream floods could have wandered in a relatively wide floodplain: only a small part of the lower watercourse was established and one bridge guaranteed the way to the ancient roman path (Fig. 9a).

The water flow of the Recco Stream was progressively modified in the second half of the XIX century, and the watercourse trend changed from a wandering to channel path. The Recco main settlements developed towards north-west (Fig. 9b). 
Later, farming activities were abandoned as people moved to urban areas in the early 20th century, which caused rapid urbanisation of the flood plain. Subsequent decreases in runoff time, deterioration of terraced areas and loss of land protection structures caused additional instabilities.

In the first decades of the XX century, the Recco Stream floodplain was almost entirely urbanized, with a clearly planned road network (Fig. 9c).

At the present day the Recco waterstream is completely channelled, mostly in the lower part where the riverbed appears shifted towards south-east. In a short part, just before the river mouth, the watercourse has been covered. The floodplain nowadays is entirely urbanized, as well as the main alluvial fan in right bank side (Fig. 9d).

In this case study we can observe an increased risk connected to watercourse network changes and population growth.

Environmental policy measures have been established only very recently to manage the areas that are abandoned and covered by shrubby, infesting plants. These areas require reclamation, resettlement and re-establishment of the natural slope conditions.

The infiltration model mentioned above showed a wide diffusion of susceptibility of the slopes to instability triggers, determined even by unexceptional rainfall, so that it needs to analyse cover characteristics such as height, grain size distribution, and permeability for stability analysis in the GIS based model.

\section{Conclusions}

The case study that has been analysed here regards the relationship between heavy rainfall and geomorphological risk in a valley of Liguria, which can be considered typical of the Mediterranean coastal areas, in terms of both geomorphological and human impact.

A short, intense precipitation event occurred on 1 June 2007, along the middle and lower parts of the Recco Stream catchment. Over about three hours, almost four times the mean monthly rainfall was recorded.

This event triggered widespread slope instability and caused a considerable series of debris flows and shallow landslides. At the same time, it caused criticality in the shallow outflows that are afferent to the secondary hydrographic network.

Some lessons are learnt from this case study.

Although rainfall event analysis can be associated with a return period of $500 \mathrm{yr}$, the actual frequency of these phenomena is much higher as it was demonstrated by the events that occurred over the last decade.

In this situation, the Basin Master Plan must be significantly improved in different ways, such as those proposed in this paper, which can be effective for this case study.
These analyses must take into consideration the hydraulic conditions along with granulometric and permeability characteristics of soils by applying a GIS environment as a modelling tool.

Finally, it is essential to use such a model also to assess the influence of the morphometric and hydraulic characteristics of the secondary hydrographic network on the risk level, because this network, which flows along underextended canals, was insufficient for appropriately draining the outflows.

Acknowledgements. We wish to thank Mauro Piccazzo for the careful reading of the manuscript and for the helpful suggestions. The authors would like to thank the three anonymous referees and Fabio Luino as editor for their constructive suggestions to improve the quality of this paper.

Edited by: F. Luino

Reviewed by: three anonymous referees

\section{References}

Caine, N.: The rainfall intensity-duration control of shallow landslide and debris flow, Geograf. Ann., 62, 23-27, 1980.

Cancelli, A. and Nova, R.: Landslide in soil debris cover triggered by rainstorm in Valtellina (Central Alps -Italy), Proc. IV ICFL, International Conference and Field Workshop on Landslide, Tokyo, 267-272, 1985.

Cevasco, A., Sacchini, A., Robbiano. A., and Vincenzi, E.: Evaluation of rainfall thresholds for triggering shallow landslides on the Genoa municipality area (Italy). The case study of the Bisagno valley, Italian J. Eng. Geol. Environ., 1, 35-50, 2010.

Corsi, B., Elter, F. M., and Giammarino, S.: Structural fabric of the Antola Unit (Riviera di Levante, Italy) and implications for its alpine versus Apennine origin, Ofioliti, 26, 1-8, 2001.

Crosta, G.: Rainfall thresholds applied to soil slips in alpine and prealpine areas, in: Proceedings of 1st International Symposium on Protection and Development of the environment in Mountains Areas, Ponte di Legno, 20-24 June, Montana s.r.l., Milano, 141153, 1994.

Crosta, G.: Regionalization of rainfall thresholds: an aid to landslide hazard evaluation, Environ. Geol., 35, 131-145, 1998.

Crosta, G. and Frattini, P.: Rainfall thresholds for triggering soil slips and debris flow, Mediterranean Storms, Proc. EGS 2nd Plinius Conference, Siena, October 2000, 463-487, 2000.

Crozier, M. J.: Landslide: causes, consequences and environment, Routledge, London, UK, 1986.

Cruden, D. M. and Varnes, D. J.: Landslide types and processes, Landslides, in: Investigation and Mitigation, Transportation Research, edited by: Turner A. K., Shuster, R. L., Board Special Report 247, National Academy Press, WA, 36-75, 1996.

Faccini, F., Brandolini, P., Robbiano, A., Perasso, L., and Sola, A.: Fenomeni di dissesto e precipitazioni in rapporto alla pianificazione territoriale: l'evento alluvionale del novembre 2002 nella bassa val Lavagna (Liguria orientale), Geografia Fisica e Dinamica Quaternaria, Suppl. VII, 145-153, 2005.

Faccini, F., Firpo, M., Robbiano, A., and Sacchini, A.: Rischio idrogeologico e dinamica degli alvei fluviali in rapporto agli interventi antropici: il caso del Torrente Bisagno a Genova, 
Engineering, Hydro, Environmental Geology, 14, suppl. B, 110111, 2012.

Faccini, F., Piccazzo, M., and Robbiano, A.: Natural hazards in San Fruttuoso of Camogli (Portofino Park, Italy): a case study of a debris flow in a coastal environment, Italian J. Geosci., 128, 641-654, 2009.

Gaussen, H.: L'étude des climats par les courbes ombrotermiques, L'information geografique, XX, 191-193, 1956.

Giannecchini, R.: Relationship between rainfall and shallow landslides in the southern Apuan Alps (Italy), Nat. Hazards Earth Syst. Sci., 6, 357-364, doi:10.5194/nhess-6-357-2006, 2006.

Green, W. H. and Ampt, C.: Studies on soil physics, I. Flow of air and water through soils, J. Agr. Sci., 4, 1-24, 1911.

Gumbel, E. J.: The return period of floods, Ann. Mat. Statist., XII, 163-190, 1941.

Gumbel, E. J.: Statistics of extremes, New York Columbia University Press, 357 pp., 1958.

Guzzetti, F., Peruccacci, S., Rossi, M., and Stark, C. P.: The rainfall intensity - duration control of shallow landslides and debris flows: an update, Landslides, 5, 3-17, 2008.

Intergovernmental Panel of Climatic Change (IPCC): Climate change 2007: the physical science basis, in: Contribution of Working Group I to the fourth assessment report of the intergovernmental panel of climatic change, edited by: Solomon, S., Qin, D., Manning, M., Chen, Z., Marquis, M., Avery, K .B., Tignor, M., and Miller, H. L., Fourth Assessment report Cambridge University Press, Cambridge, UK and New York, USA, 2007.

Jakob, M. and Lambert, S.: Climate change effects on landslides along the south-west coast of British Columbia, Geomorphology, 107, 275-284, 2009.

Luino, F.: Sequence of instability processes triggered by heavy rainfall in the northern Italy, Geomorphology, 66, 13-39, 2005.

Muntohar, A. S. and Jiuan Liao, H.: Rainfall infiltration: infinite slope model for landslides triggering by rainstorm, Nat. Hazards, 54, 967-984, 2010.
Pasquale, V., Russo, G., Sacchini, A., and Verdoya, M.: Precipitation rate as a signal of recent climatic variations, Annalen der Meteorologie, 30, 278-281, 1994.

Pradel, D. and Raad, G.: Effect of permeability on superficial stability of homogeneous slopes, J. Geotech. Eng., 119, 315-332, 1993.

Provincia di Genova: Piano di Bacino D. L. 180/1998, Ambito 15, Approvato con Delibera del Consiglio Provinciale no. 67 del 12.12.2002. Available at http://cartogis.provincia.genova.it/ cartogis/pdb/ambito15, 2002.

Russo, G., Eva, C., Palau, C., Caneva, A., and Sacchini, A.: The recent abrupt increase in the precipitation rate as seen in an ultracentennial series of precipitation, Il Nuovo Cimento C, 23, 3952,2000

Sacchini, A., Faccini, F., Firpo, M., Bozzano, S., Francioli, G., and Robbiano, A.: Heavy rainfall triggering flash floods and shallow landslides: the case study of a Ligurian event (4th October 2010), Abstract volume of 13th Plinius Conference on Mediterranean Storms, Egu Topical Conference Series, Savona 7-9 September 2011, 19-20, 2011.

Sassa, K.: The geotechnical classification of landslides, Proc. IVth International Conference and Workshop on Landslides, Tokyo, 31-40, 1985.

Servizio Geologico d'Italia: Carta Geologica d'Italia in scala 1:100.000, Foglio 83 (Rapallo), Iio Edizione, 1968

Van Zutphen, A. C. A., Van Wamel, W. A., and Bons, A. J.: The structure of the Lavagna Nappe in the region of M. Ramaceto and Val Graveglia (Ligurian Apennines, Italy), Geologie en Mijubouw, 64, 373-384, 1985.

Varnes, D. J.: Slope movements types and processes,Landslides, analysis and control, in: Transportation Research Board Special Report No. 176, edited by: Schuster, R. L., and Krizek, R. J., National Academy of Sciences, 11-33, 1978.

Varnes, D. J.: IAEG Commission on Landslides: Landslides Hazard Zonation: a review of principles and practice, UNESCO, Paris, 1984. 